\title{
Bioreactor Simulation with Quadratic Neural Network Model Approximations and Cost Optimization with Markov Decision Process
}

\author{
Tamás Koncsos ${ }^{1 *}$ \\ ${ }^{1}$ Department of Sanitary and Environmental Engineering, Faculty of Civil Engineering, Budapest University of Technology and \\ Economics, H-1111 Budapest, Műegyetem rkp. 3., Hungary \\ * Corresponding author, e-mail: tamas.koncsos@vkkt.bme.hu
}

Received: 23 July 2019, Accepted: 24 February 2020, Published online: 06 May 2020

\begin{abstract}
The efficient operation of activated sludge type wastewater treatment plants is an ongoing topic for the utility providers, where electric energy consumption shares are high, giving cca. $30 \%$ of total operational costs. Intervention methods for intensification include fine tuning of aeration settings, sludge removal and the adjustment of recirculation rates. In order to analyze the effects of various process control strategies, activated sludge models (ASM) are used for the purpose of biokinetic modeling. In practice, most model simulators do not incorporate optimization and necessary auto-calibration of the latter, due to high computational demand of timeseries evaluation. In this paper, a new mathematical model is presented, which makes biokinetic simulations suitable for the use in decision support systems. Namely, the ASM model is approximated with a computanional inexpesive quadratic model solution, fed into a set of mass-balance corrected neural networks. Cost optimization is achieved with Markov decision process model. The developed method was illustrated for a case of Hungarian, large wastewater treatment plant. It was proven, the model is able to find better aeration schemes for the plant in aspect of cost of operation and nitrogen removal efficiency. The model can be used to find cost-optimal policies under arbitrary defined conditions. As a benefit, results can be implemented into industrial logic controllers.
\end{abstract}

Keywords

wastewater treatment, neural network model, Markov decision process, cost optimization

\section{Introduction}

Biological wastewater treatment plants are suitable for removing organic matter and plant nutrients efficiently. However, the operator is further interested in minimizing costs of the activated sludge system, where immediate intervention options are available and can be achieved: by fine tuning of aeration with the adjustment of cycle times or setting threshold levels by monitored nutrient levels in the reactor. Sludge recirculation intensity and chemical dosing adjustments are also viable options. The electric energy consumption related to the maintenance of the biomass in the activated sludge reactors by aeration usually exceeds $35-75 \%$ of the total electric energy demand $[1,2,3]$. As for the biomass, a widely used tool for analyzing kinetics on model level are the Activated Sludge Models (ASM) developed by the international research team IAWPRC [4]. These models describe processes in the reactors of the wastewater treatment plants. Some variants are the ASM1 [4], ASM2d [5],
ASM3BioP [6], Barker-Dold model [7]. ASM1 describes the process of organic matter and nitrogen removal, other listed models in latter also implement biological phosphorus removal. Engineering simulators, such as Biowin, Simba, WEST, GPS-X to name a few are dependent on these models. Oxygen dissolution models might be combined with the ASM, in order to determine energy demands directly [8].

It is worth mentioning, engineering simulators are usually limited to biological process simulation and usually do not imply optimum search (eg. parameter estimation) methods. In contrast to this, the presented method is built upon the latter, to achieve the role of a decision support system. Optimum search is based on computational expensive iterations: A single operating scheme means the evaluation of a long time series. In frame of the present work a new method is introduced which can boost computation speed by an order of magnitude. 
The method is based on the concept of finding alternative explicit equations to the ASM differential equation system in combination with neural networks. The method involves second order approximations for the differential equation's initial conditions, describing the perfectly stirred reactor. The challenge was to deal with the problems of mass conservation related to the neural networks errors in predictions. A post-correction method was used to minimize the mass balance error.

The presented model is then used as a DSS where the application of Markov decision processes (MDP) is applied to find best economical operations. The solution of the MDP is represented as a policy matrix (a control scheme for a custom system control, for instance: aeration or recirculation). The solutions describe which interventions are recommended for a given system state in order to achieve a long-term cost minimum in parallel with efficient biokinetic process control. The new model methodology is applied on the analysis of a large wastewater treatment plant located in Hungary.

\section{Methodology}

\subsection{The bioreactor and clarifier model}

In order to model any activated sludge type wastewater treatment plant (either for any continuous flow or SBR system), it is necessary to describe the biokinetic models in the reactors as well as settling in the clarifier. Reactor processes were modelled by ASM models. Here the EAWAG ASM3 bioP model [6] was used (17 state variables describing wastewater fractions by 23 processes [9]). In the case of a continuously stirred reactor (CSTR) Eq. (1) applies for each wastewater fraction.

$$
\frac{d \underline{C}}{d t}=\underline{r}(C)+\frac{Q}{V}\left(\underline{C}_{i n f}-\underline{C}\right), \underline{C}=\left[c_{1}, . ., c_{n}\right]
$$

$\underline{r}(C)$ is the source member from the Gujer matrix. The Gujer matrix is the descriptor for biological and chemical reactions for wastewater treatment reactors (in general also called as Petersen matrix). The matrix representation is a compact form of a selected activated sludge model. From there each fraction can be expressed as an equation substituted into $\underline{r}(C)$ vector. $C_{i n f}$ is the concentration of a wastewater component in the influent, $\underline{C}$ is the concentration vector of the effluent, $Q$ is the influent and effluent flowrate, $\mathrm{V}$ is the volume of the reactor. CashKarp predictor-corrector method was used to solve the differential equations.
The clarifier is usually modelled in 1D [10]. The concentration formula of the $1 \mathrm{D}$ settling according to the partial differential Eq. (2) is as followings:

$$
\begin{aligned}
& \frac{\partial C(z, t)}{\partial t}=-\frac{\partial(F(C(z, t), z, t)}{\partial z} \\
& +\frac{\partial}{\partial z}\left(D(z, t) \cdot \frac{\partial C(z, t)}{\partial z}\right)+s(z, t) .
\end{aligned}
$$

In Eq. (2), $z$ is depth, $t$ is time, $D$ stands for dispersion. Dispersion can be assumed to be zero, if there is low turbulence in the settler or if the effect of mixing of sediments is negligible compared to the sedimentation settling flux. The right-hand first negative member of the equation indicates a change in the concentration of a differentially small layer by sedimentation and flow-through flux, $s(z$, $t$ ) stands for a sediment source (e.g. in an influent layer). By dividing the settler into $N$ number of layers, the partial differential equation can be simplified to ordinary differential equation system.

\subsection{Substitution of differential equations with neural network models}

\subsubsection{Quadratic approximation}

The first part of the objectives described is to achieve computational speed up. Supposing we can approximate the dependency of state variables with second order (quadratic) Eq. (3) on the interval $[0, \mathrm{~T}]$ time step:

$$
\begin{aligned}
& c_{i}^{(t)}=c_{i}^{(t=0)}+b_{i} t+d_{i} t^{2} \\
& (0<t<T) \\
& \underline{C}=\left[c_{1}^{(t)}, \ldots, c_{n}^{(t)}\right],
\end{aligned}
$$

where $t$ is time for $T$ time step, $c_{i}^{(t)}$ is the effluent concentration of the reactor for an i-th component and $b_{i}$ and $d_{i}$ are parameters we are looking for. Following criteria have to be satisfied:

The polynomial approximation should fit at time, $t=0$ and at the end of the chosen time step: $c_{i, \text { quad }}^{(0)}=c_{i}^{(0)}$ and $c_{i, q u a d}^{(T)}=c_{i}^{(T)}$.

The quadratic model approximation for mass balance should be valid for any $T$ time step. The integral of concentrations in a short time step multiplied with the flow rate describes the effluent mass from the reactor, which should be equal with the second order approximation, described by Eq. (4). 


$$
\begin{aligned}
& Q \int_{0}^{T} c_{i} d t=Q\left(c_{i}^{(t=0)} T+b_{i} \frac{T^{2}}{2}+d_{i} \frac{T^{3}}{3}\right) \\
& \int_{0}^{T} c_{i} d t \approx S_{A S M, i}
\end{aligned}
$$

The integral of concentrations for a time step however, can be calculated based on a chosen numerical method symbolled as $S_{A S M, i}$ in Eq. (5). The numerical method could be Euler, Runge-Kutta 4, or predictor correctors for instance: Dormand-Prince, Fehlberg [11], Cash-Karp [12].

The flow rate $\mathrm{Q}$ is considered to be constant in a single time step and it is assumed that the inflow flux of the reactor can be described as a quadratic polynomial function of time similarly to Eq. (3).

$c_{\text {inf }, i}^{(t)}=c_{\text {inf }, i}^{(t=0)}+b_{i n f, i} t+d_{i n f, i} t^{2}$

If the differential equation solution is known in the time interval 0-T, then $b_{i}, d_{i}$ parameters can be determined from the Eq. (3) and Eq. (4), Eq. (5) as following:

$$
\begin{aligned}
& b_{i}=2 \frac{3\left(S_{A S M, i}-c_{i}^{(T=0)} T\right)-\left(c_{A S M, i}^{(t=T)}-c_{i}^{(t=0)}\right) T}{T^{2}}, \\
& d_{i}=3\left(\frac{c_{A S M, i}^{(t=T)}-c_{i}^{(t=0)}}{T^{2}}-\frac{2\left(S_{A S M, i}-c_{i}^{(t=0)} T\right)}{T^{3}}\right) .
\end{aligned}
$$

The ASM model is calculated for a large set of initial conditions and $b_{i}$ and $d_{i}$ values with classical numerical method (Cash-Karp method was used) for each wastewater fraction. These parameters describe the approximation curvature of concentration change in Eq. (3) for a time step $T$.

The second part involves the use of neural networks. The goal is to train the neural network: the very large set of initial conditions are set as inputs while $b_{i}$ and $d_{i}$ values are set as the desired outputs: Following the training phase, the neural network should be able to predict results for each initial condition. With the presented method, there is no further need to use the ASM differential equations, while proper approximation can be achieved, as clarified in the next section.

\subsubsection{Use of neural networks with the quadratic model} Some neural networks like the multi-layer perceptron (MLP) can be used in universal approximation tasks of non-linear functions [13], they are similar tools like nonlinear regression methods. The MLP incorporates supervised learning, in this case an arbitrary large set of input and output pairs of vectors are needed. For evaluating results only input vectors are necessary. In our case, the input matrix can be described as following considering all initial conditions:

$\underline{\underline{A B D}}^{C, i n f}=\left[\begin{array}{l}c_{i n f_{1}}, . ., c_{i n f_{n}} \\ b_{i n f_{1}}, . ., b_{i n f_{n}} \\ d_{i n f_{1}}, . ., d_{i n f_{n}}\end{array}\right], \underline{\underline{A B D}}{ }^{C, i n f} \in H_{1}$

and $\underline{C}_{0}=\left[\begin{array}{lll}c_{1}^{(t=0)} & , \ldots, & c_{n}^{(t=0)}\end{array}\right], \underline{C}_{0} \in H_{2}$.

For each initial condition $A B D^{C, i n f}$ matrix describes the influent concentration, also with a second order approximation characteristics. $\underline{C}_{0}$ vector holds the initial concentrations for the reactor at time zero. Note, that $A B D^{C, i n f}$ can be transformed to a single column vector. $\overline{\overline{H_{1} \text { and }}} H_{2}$ sets will be refered as, the input set for the neural network:

$H_{\text {in }}=\underline{A B D}^{C, \text { inf }} \in H_{1}, \quad \underline{C}_{0} \in H_{2}$

The transformation to be achieved by the neural network is:

$f: H_{\text {in }} \stackrel{t=T}{\rightarrow} H_{\text {out }}$,

where

$\underline{\underline{A B D}}^{C, e f f}=\left[\begin{array}{l}b_{i 1}, . ., b_{\text {in }} \\ d_{i 1}, . ., d_{\text {in }}\end{array}\right], \underline{\underline{A B D}}^{C, \text { eff }} \in H_{\text {out }}$.

$A B D^{C, e f f}$ can also be rewritten as a column-vector. All $b_{1}, \ldots, b_{n}$ and $d_{1}, \ldots, d_{n}$ can be calculated for each initial condition based on the evaluation of the ASM model as described by Eq. (7). Basically, the neural network learns how to generate parameters for the second order approximation, it can boost simulation by finding a computationally less demanding explicit solution for the original model. The computational demand is reduced by the magnitude of difference in complexity of the original numerical evaluation and the neural network expressed as an explicit equation. The approximation method was determined for different time steps and checked if the selected model is valid for extrapolation. Table 1 summarizes the single-step correlation results for several components (dXH - Heterotrophic bacteria, dXPP- Poly-Phoshate, dSSSoluble carbonaceous material, $\mathrm{dSNH}_{4}-\mathrm{Ammounium}-\mathrm{N}$ and $\mathrm{dSNO}_{3}-$ Nitrate-N), both 5 and 10 minute interpolation and extrapolation (forecast) is shown. 
Table 1 Correlation between ASM and quadratic neural approximation for a single timestep. dXH (heterotrophic bacteria), dXPP (polyphosphate), dSS (Dissolved biodegradable COD ), $\mathrm{SNH}_{4}\left(\right.$ Ammonium-N), $\mathrm{dSNO}_{3}$ (Nitrate-N)

\begin{tabular}{lccccc}
\hline Component & $\begin{array}{c}\mathrm{dT}=5 \text { (interpolation) } \\
\mathrm{T}=0-5 \mathrm{~min} \mathrm{R}^{2}\end{array}$ & $\begin{array}{c}\mathrm{dT}=5 \text { (extrapolation) } \\
\mathrm{T}=0-5 \min \mathrm{R}^{2}\end{array}$ & $\begin{array}{c}\mathrm{dT}=10 \text { (intepolation) } \\
\mathrm{T}=0-10 \text { min } \mathrm{R}^{2}\end{array}$ & $\begin{array}{c}\mathrm{dT}=10 \text { (extrapolation) } \\
\mathrm{T}=10-15 \text { min } \mathrm{R}^{2}\end{array}$ & $\begin{array}{c}\mathrm{dT}=10 \text { (extrapolation) } \\
\mathrm{T}=10-20 \mathrm{~min} \mathrm{R}^{2}\end{array}$ \\
\hline $\mathrm{dXH}$ & 0.999 & 0.998 & 0.998 & 0.998 & 0.982 \\
$\mathrm{dXPP}$ & 0.985 & 0.975 & 0.991 & 0.981 & 0.966 \\
$\mathrm{dSS}$ & 0.987 & 0.925 & 0.941 & 0.905 & 0.843 \\
$\mathrm{dSNH}_{4}$ & 0.999 & 0.990 & 0.999 & 0.967 & 0.923 \\
$\mathrm{dSNO}_{3}$ & 0.999 & 0.990 & 0.999 & 0.968 & 0.934 \\
\hline
\end{tabular}

\subsection{Mass balance error correction}

While the quadratic model deduced was free of mass balance errors, the neural network will result in some prediction failures, systematic errors. The MLP neural network can be rewritten as [14] a simple explicit Eq. (12) (for a 2 layer $\mathrm{ANN}$ ):

$Y_{k}=f_{2}\left(b_{2}+\sum_{j=1}^{m}\left[f_{1}\left(b_{1}+\sum_{i=1}^{n}\left[X_{i} \cdot w_{i j}\right]\right) \cdot w_{j k}\right]\right)$,

where $Y_{k}$ is the output vector, $X_{i}$ the input vector, and a $w_{i j}$ and $w_{j k}$ are weights calibrated throughout the training phase. The neural network will either over or underestimate real values of $b_{i}$ and $d_{i}$ by a relatively small error. The idea of using the MLP for substitution of the original model is based on iterations. Each iteration evaluates the model by a time step $T$. The time step should be as large as possible, results show good approximation if a time step is between 5-20 minutes. The problem arises if the neural network uses previous solutions of its own results (from earlier predictions): in this case the error will accumulate since network evaluation is always dependent on the initial conditions. Error accumulation tests of $\sim 100000$ hours have been simulated: the error does not follow normal distribution as supposed. However, depending on the initial conditions a polynomial error function approximation can be determined based on $\Delta c_{i}$ (concentration change for a $T$ time step).

The suggested correction method is based on comparisons between the results of the quadratic-neural model and the differential equation system solved by classical numerical method. But only at chosen iteration steps are both solutions compared with each other. Extent of the error is then approximated with an $\mathrm{n}$ order polynomial fit. If only quadratic model is used, $\Delta c$ is predicted and corrected with the negative of the error function. In this example, model comparisons were made at ratio 1:20 iteration, which means that for every twenty iterations only one comparison and error prediction was made. Previously, correction methods were tested with cases using ratios of 1:5, 1:10, 1:20, 1:50 and 1:100. 1:20 ratio was a compromise between relative good mass balance error and fast computation speed, the relative error was $\Delta \mathrm{E}<2.3 \%$. Fourth order polynomial function fitting on the absolute error are depicted for the case of ammonium-N Fig. 1 and nitrate-N Fig. 2. By applying the correction method during simulation, concentrations of the differential equation model and the quadratic model showed good correlation, shown on Fig. 3 and Fig. 5. Approximation of the ASM model is also depicted in timeseries for the case of ammonium-N (Fig. 4) and nitrate-N (Fig. 6).

\subsection{Markov decision processes}

The goal of the research was to find a good approximation with low computational demand. By achieving this milestone, it got convenient to use this tool for determining the outcome of timeseries in the case of large number of scenarios. These solutions also allow for calculation of costs and expenditures (related to electric energy consumption, environmental fees, etc.). The final goal however is to find the best control scheme, the cheapest solution for long term operation, with minimal risks. In this paper, Markov Decision Process theory is proposed for the task [15].

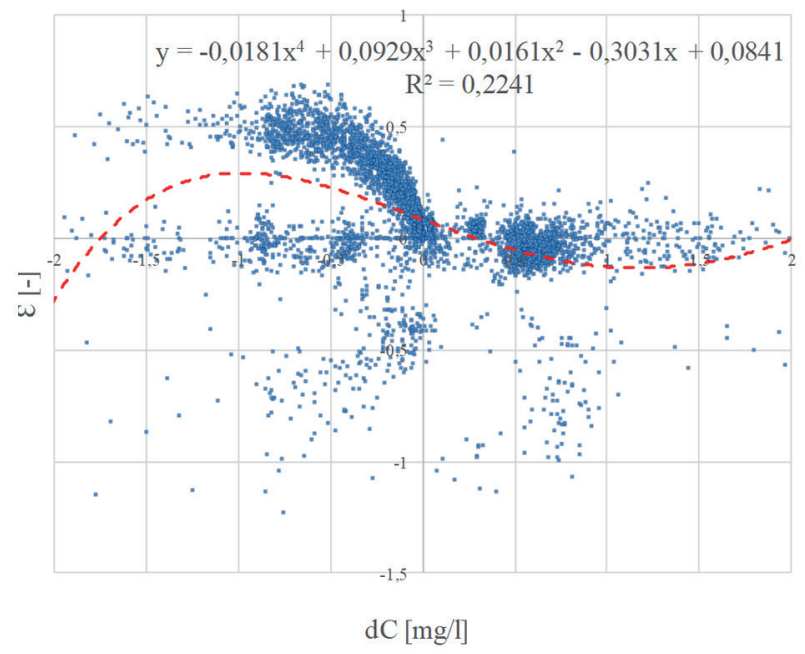

Fig. 1 The absolute error as a function of $\Delta c_{i}\left(\mathrm{dSNH}_{4}\right)$ 


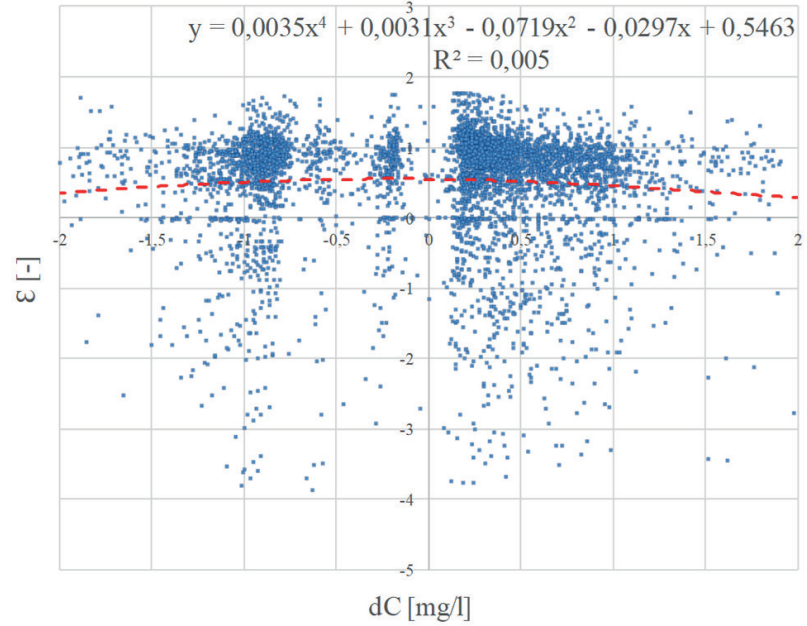

Fig. 2 The absolute error as a function of $\Delta c_{i}\left(\mathrm{dSNO}_{3}\right)$

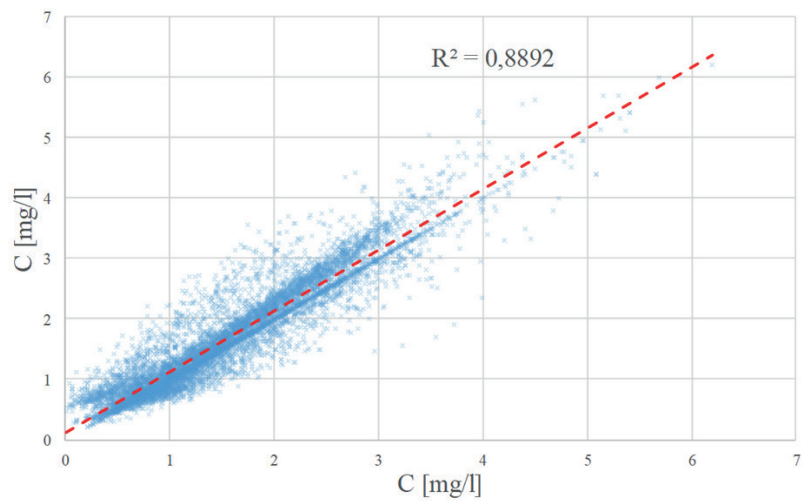

Fig. 3 Approximation of the ASM model using mass balance correction method. Correlation of quadratic ANN with ASM $\left(\mathrm{NH}_{4}-\mathrm{N}\right)$

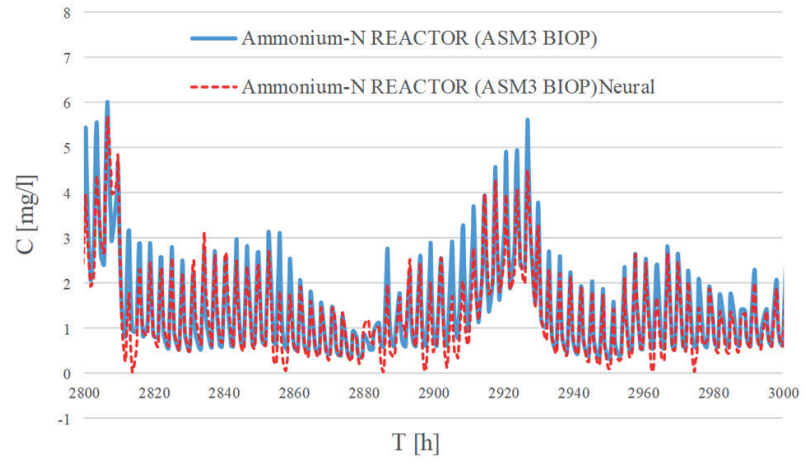

Fig. 4 Approximation of the ASM model using mass balance correction method. Timeseries simulation comparison $\left(\mathrm{NH}_{4}-\mathrm{N}\right)$

By improving simulation speed to a greater extent, several hundred years of model time could be simulated efficiently allowing for detailed scenario analysis. Influent timeseries were generated based on autoregressive method [16]. Markov decision processes (MDP) was implemented into the simulator. The MDP first became known by Bellman in 1957 and was initially used for optimum production tasks and logistics. The Markov decision process is a discrete-time stochastic process control theory. Similar to Markov chains, it is supposed that so called states Si may describe a system: A stochastic process has the Markov property if the conditional probability distribution of future states depends only upon the present state, not on the sequence of events in the past. MDP implements so called actions that might change the system process to another state with a given probability. A state for instance can be the combination of wastewater fractions monitored at different levels (Fig. 7).

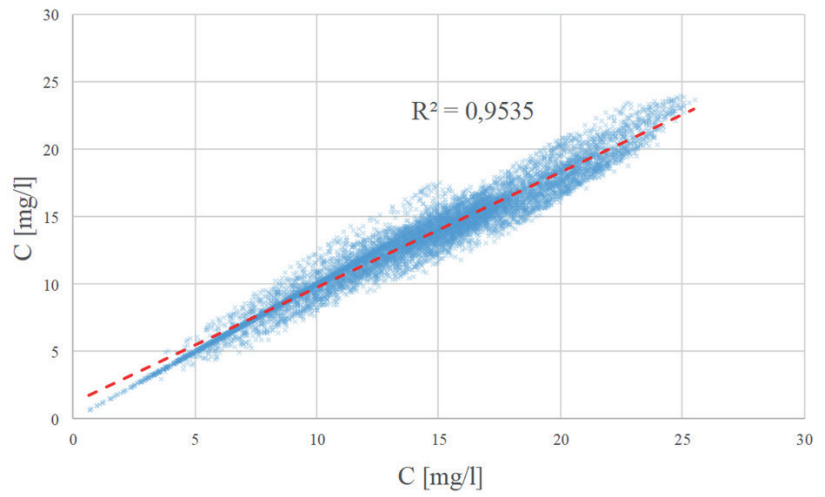

Fig. 5 Approximation of the ASM model using mass balance correction method. Correlation of quadratic ANN with $\mathrm{ASM}\left(\mathrm{NO}_{3}-\mathrm{N}\right)$

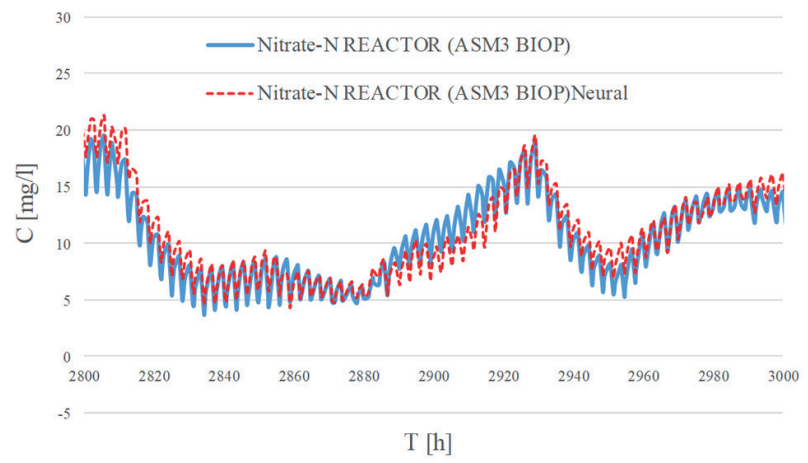

Fig. 6 Approximation of the ASM model using mass balance correction method. Timeseries simulation comparison $\left(\mathrm{NO}_{3}-\mathrm{N}\right)$

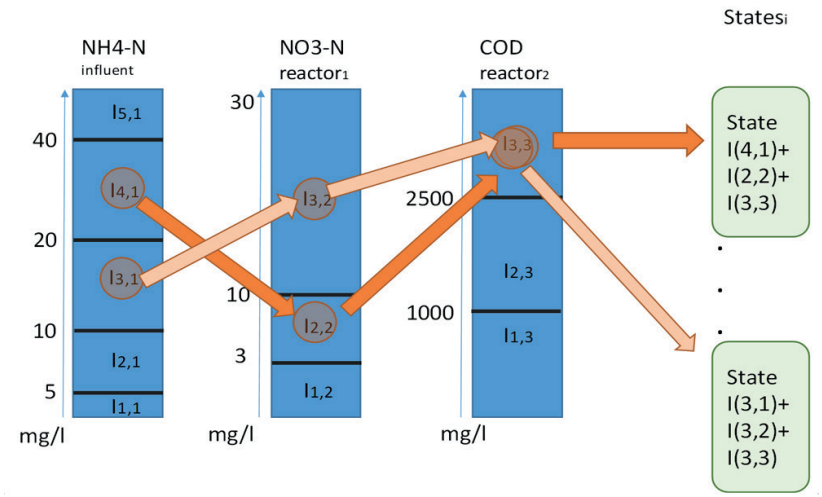

Fig. 7 Markov States are formulated as combination of chosen wastewater variable concentration intervals. The path of arrows show that each state is a set of intervals from different wastewater fractions 
An action is written as $P_{a}\left(s, s^{\prime}\right)$ indicating the probability of state change from $s$ to $s^{\prime}$. Such action could be the adjustments for aeration levels or setting flow rates in recirculations, etc. MDP also implements revenues $R(S)$ for each state. In our example for each reactor state, an expenditure can be defined, such as cost of aeration, environmental fee based on current effluent quality, as well as fines, if conditions for effluent quality are not met within the wastewater treatment plant. These are negative values in aspect of revenues. It's worth to note that short term actions leading to higher revenues do not necessarily mean best revenues in long terms. To calculate optimum choice, the Bellman equation were evaluated by Howard's policy iteration method [17], shown in Eq. (13). In the Bellman equations, $\pi_{i}(s)$ stands for action adopted as a policy and $U^{\pi_{i}}\left(s^{\prime}\right)$ is the revenue of all policies applied in the future steps. The way to formulate previously presented neural network solutions for MDP was according to the following steps in practice:

1. Large number of timeseries were generated based on the neural networks solutions for quadratic parameters. Autoregressive (AR) method was implemented to generate influent wastewater qualities and random selected actions (aeration settings) were applied.

2. $T=5 \mathrm{~min}$ as time step was selected for the model.

3. Several states $S$ were defined by selecting relevant wastewater variable concentration intervals. For each state, operation costs and environmental fees could be calculated as revenues $U^{\pi_{i}}(s)$.

4. The long term evaluation of the ASM model allowed to find probabilities of state changes $P_{a}\left(s, s^{\prime}\right)$.

5. The Bellman equation was solved.

\subsection{Wastewater treatment plant layout}

The wastewater treatment plant, subject to this study, is located in a metropolitan area in Hungary (for confidential reasons, the location will not be specified). The pre-denitrification type WWTP has a parallel allocation regarding sludge recirculation, as shown in Fig. 8. The biological treatment is preceded by mechanical treatment consisting combined primary settling facility (pretreatment functions are grit removal, grease removal and settling in one single work using separate dedicated areas). The biological treatment starts with a pre-anoxic and anaerobic zone each having a volume of $2000 \mathrm{~m}^{3}$. It is followed by an oxidation ditch type reactor with a volume of cca. $9000 \mathrm{~m}^{3}$ and depth of $10 \mathrm{~m}$. Each wastewater treatment batch has a capacity of approximately 50000 PE.

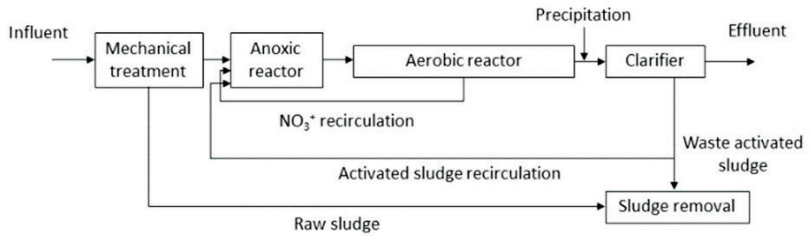

Fig. 8 Plant layout in the model

The aerated reactor has an anoxic-aerobic cycle time with a ratio of 1:2, which may vary depending on influent load of COD and $\mathrm{NH}_{4}-\mathrm{N}$. Dissolved oxygen level is controlled by PLC providing a $2 \mathrm{mg} / 1$ dissolved oxygen concentration on average. Based on the influent flow, the nitrate recirculation has a setpoint of $100 \%$ rate in side flow. The lower rate of recirculation is due to achieve better biological phosphorus removal. (Additional phosphorous removal is achieved by copper chloride chemical precipitation). The sludge age exceeds ten days and has a setpoint of $3.1 \%$ of influent flow on average.

The clarification is achieved via horizontal flow type architecture with a length of $60 \mathrm{~m}$ and depth of more than $5 \mathrm{~m}$. The clarifier has a skimmer that travels back and forth pumping settled activated sludge into a surface channel. Effluent wastewater quality is regulated for COD, total $\mathrm{N}, \mathrm{NH}_{4}-\mathrm{N}$ and $\mathrm{PO}_{4}-\mathrm{P}, \mathrm{TP}$. Concentration limits are described in the 220/2004. (VII. 21.). Hungarian government regulation, while environmental fee is defined by the 2003. LXXXIX. law [18]. Note, that the wastewater treatment plant has also anaerobic sludge digestion utility and available cogeneration gas-motors burning biogas. Leachate liquor is pumped back to the mechanical treatment process.

\section{Results}

In the first step, a calibration of the ASM model [19] was achieved. Only three on-site measurements were available for the reactors, however daily data was provided by the WWTP laboratory on influent and effluent characteristics (Q, temperature, $\mathrm{COD}, \mathrm{NH}_{4}-\mathrm{N}, \mathrm{NO}_{3}-\mathrm{N}, \mathrm{TP}, \mathrm{PO}_{4}-\mathrm{P}$ ). Using the calibrated model, the quadratic model coefficients were generated for each initial condition during simulation. The quadratic-neural model was trained, timestep was set to 5 minutes, resulting in an approximation for the particle model components, with a minimal mass balance error of $5.8 \%$ in the case of ammonium and nitrate, $2.6 \%$ for COD and $4.4 \%$ for orthophosphate. The quadratic model was validated on the daily measurements of the wastewater treatment plant. Fig. 9 and Fig. 10 show simulation results for effluent TN and measured TN concentrations. 


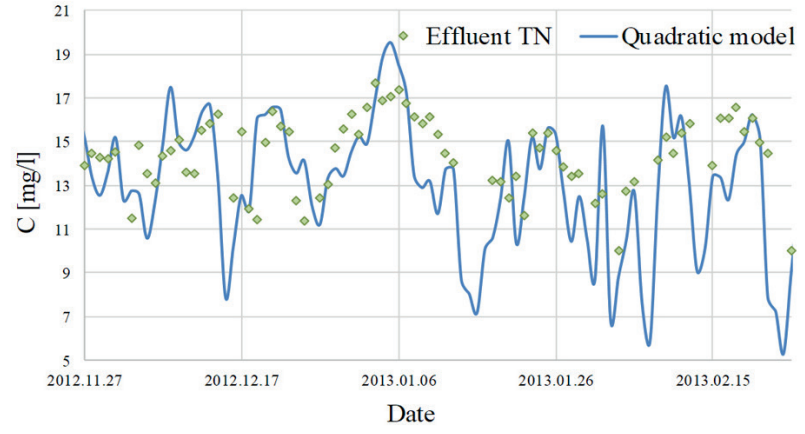

Fig. 9 Effluent TN: measured vs quadratic results (1)

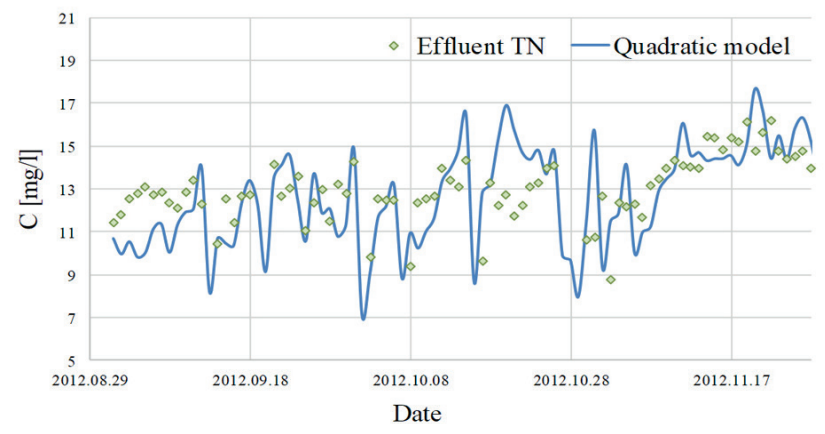

Fig. 10 Effluent TN: measured vs quadratic results (2)

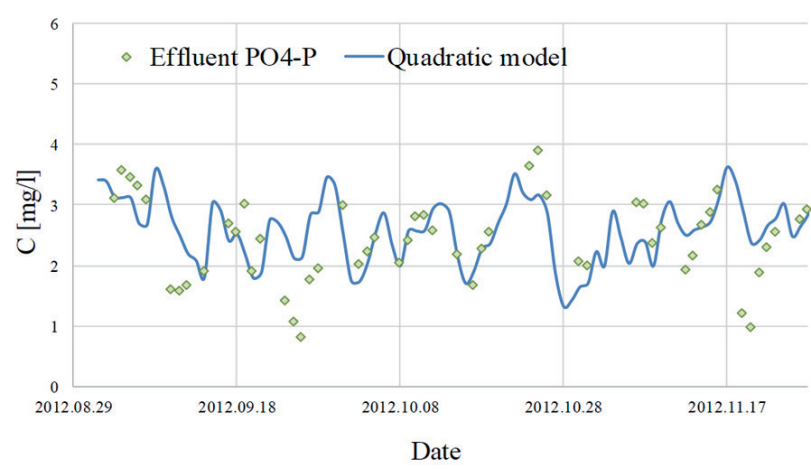

Fig. 11 Effluent $\mathrm{PO}_{4}$-P: measured vs quadratic model results (1)

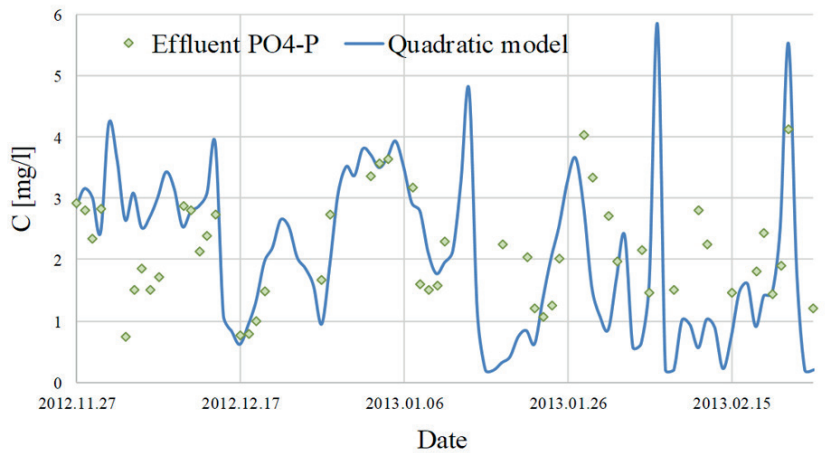

Fig. 12 Effluent $\mathrm{PO}_{4}$-P: measured vs quadratic model results (2)

Fig. 11 and Fig. 12 show simulation results for effluent $\mathrm{PO}_{4}-\mathrm{P}$ and measured orthophosphate concentrations. Validation results show, the quadratic model and the underlying ASM can be considered as adequate.
The amount of oxygen consumption was original determined by the activated sludge model combined with the oxygen depletion model [8]. The neural model was used to approximate the latter, calibrated deterministic model based on differential equations. The variation of influent wastewater characteristics were simulated with the help of the autoregressive method (AR). AR was applied in order to generate several hundred years of influent flow and wastewater quality time series [16] based on a seven-year period of available real data. The need for such long time series were due to calculate probabilities of transitions, such as extreme and unusual aeration settings (in order to examine settings of low oxygen scenarios, and also biokinetic effects at various influent scenarios). Based on nitrate, ammonium level combinations in the anoxic and aerobic reactors, the Markov states were determined (assuming that a control scheme can be applied by monitoring only some of the wastewater components). State transition probabilities of Markov processes were simulated for three different scenarios:

- In the first analysis, the aerobic reactor $\mathrm{NH}_{4}-\mathrm{N}$ and $\mathrm{NO}_{3}-\mathrm{N}$ was permitted to reach $80 \%$ of the actually environmental effluent concentration limit $(4 \mathrm{mg} / \mathrm{l}$ in the case of $\mathrm{NH}_{4}$ ).

- In the second analysis, the Markov states characterized the intermittently aerated reactor and the anoxic reactor combinations of the $\mathrm{NH}_{4}-\mathrm{N}$ and $\mathrm{NO}_{3}-\mathrm{N}$ components. A $50 \%$ level of statutory limit values was set as maximum for $\mathrm{NH}_{4}-\mathrm{N}$.

- In the third analysis, an equal cost to the original was achieved, but with lower $\mathrm{NH}_{4}-\mathrm{N}$ in the effluent as a result, meaning also a better nitrogen removal efficiency.

The limit for total nitrogen is $30 \mathrm{mg} / \mathrm{l}$, for COD is $125 \mathrm{mg} / \mathrm{l}$ which was never exceeded in any scenarios. The revenue of Markov states was determined on the basis of environmental fee, aeration costs and environmental quality standards. The result of the MDP was a policy matrix, a control scheme for aeration, which may be programmed into a programmable logic component (PLC). (For example a single policy looks like the following: If $\mathrm{NH}_{4}-\mathrm{N}>1.7 \mathrm{mg} / \mathrm{l}$ and $5 \mathrm{mg} / \mathrm{l}<\mathrm{NO}_{3}-\mathrm{N}<10 \mathrm{mg} / \mathrm{l}$ then aeration of $\mathrm{O}_{2}=1.2 \mathrm{mg} / \mathrm{l}$ level should be achieved with aeration). In the final step the policy was tested with existing time series. Comparison with the results of original aeration, showed results, summarized in Table 2. 
Table 2 Result of MDP policies, efficiency. The number of intervals in the third column represents the amount of interval split for concentration in $\mathrm{mg} / \mathrm{l}$ for a single state

\begin{tabular}{lccccc}
\hline $\begin{array}{l}\text { MDP } \\
\text { policy }\end{array}$ & $\begin{array}{c}\text { MDP } \\
\text { number of } \\
\text { policies }\end{array}$ & $\begin{array}{c}\text { Electric } \\
\text { energy } \\
\text { savings [\%] }\end{array}$ & $\begin{array}{c}\text { Cost } \\
\text { reduction } \\
{[\%]}\end{array}$ & $\begin{array}{c}\text { Effluent } \\
\mathrm{NH}_{4}-\mathrm{N} \text { as } \\
\text { average }[\mathrm{mg} / \mathrm{l}]\end{array}$ & $\begin{array}{c}\text { Effluent } \\
\mathrm{N}[\mathrm{mg} / \mathrm{l}]\end{array}$ \\
\hline 1 & - & $\begin{array}{c}\text { Bench- } \\
\text { mark }\end{array}$ & $\begin{array}{c}\text { Bench- } \\
\text { mark }\end{array}$ & 1.47 & 19.75 \\
2 & 27 & 13.5 & 22.9 & 3.95 & 9.05 \\
3 & 172 & 19.2 & 11.5 & 2.40 & 11.67 \\
4 & 170 & 11.5 & 0 & 1.20 & 16.39 \\
\hline *1 No MDP original aeration scheme, 2 Maximum savings, 3 Median \\
savings, 4 No savings but more efficient $\mathrm{NH}_{4}-\mathrm{N}$ removal
\end{tabular}

Policy No.1 stands for no custom policy, the original aeration scheme is applied. Policy No.2. denotes the first MDP analysis, where only $\mathrm{NO}_{3}-\mathrm{N}$ and $\mathrm{NH}_{4}-\mathrm{N}$ was selected as monitored states $\mathrm{S}$ from the aerobic reactor. For policy No.3, $\mathrm{NO}_{3}-\mathrm{N}$ and $\mathrm{N}_{\mathrm{H}} 4-\mathrm{N}$ was selected from both the aerobic zone the anaerobic zone. The same state variables where chosen for policy No.4.

By increasing the intensity of aeration, electricity costs increase, while denitrification capacity decreases, higher nitrate levels are expected. Electric energy expenditure for different effluent average Ammonium-N scenarios are depicted in Fig. 13, while Fig. 14 shows total expenditure. Total expenditure includes electric energy expenditures and environmental fees calculated by the effluent COD, TN and TP. Excessively low aeration will risk higher fees related to effluent water quality. The maximum savings in the analysis exceeded $20 \%$ of total costs, which can be achieved by keeping the effluent $\mathrm{NH}_{4}-\mathrm{N}$ at its maximum. The expenditure by specific $\mathrm{N}$ removal is depicted in Fig. 15 and the effluent Ammonium- $\mathrm{N}$ timeseries for different scenarios is shown on Fig. 16. Results showed that cost reduction is proportional to the effluent $\mathrm{NH}_{4}-\mathrm{N}$, but for the same operational costs, it is possible to find better solutions.

\section{Conclusions}

A new approach was presented as a method for approximation of ASM models. The differential equation system of the ASM3 bioP model was replaced by a second order solution and neural network. Computation time has been decreased by an order of magnitude, allowing convenient simulation for very long time series. The goal was to create wastewater treatment operation policies for automatic control cost efficiently: The large set of reactor operation time series were used as training data for the Markov

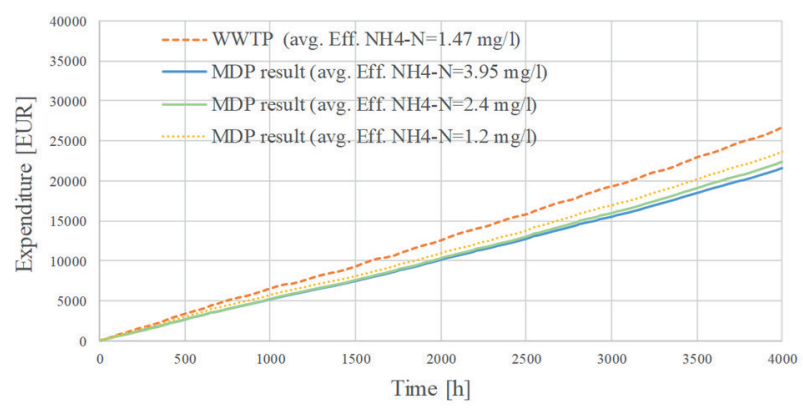

Fig. 13 Total electric energy expenditure. Red dotted curve shows the wastewater treatment's current electric energy expenditure with and average effluent ammonium-N level of $1.47 \mathrm{mg} / 1$. Note that cost reduction can be achieved with even better effluent ammonium levels (yellow curve)

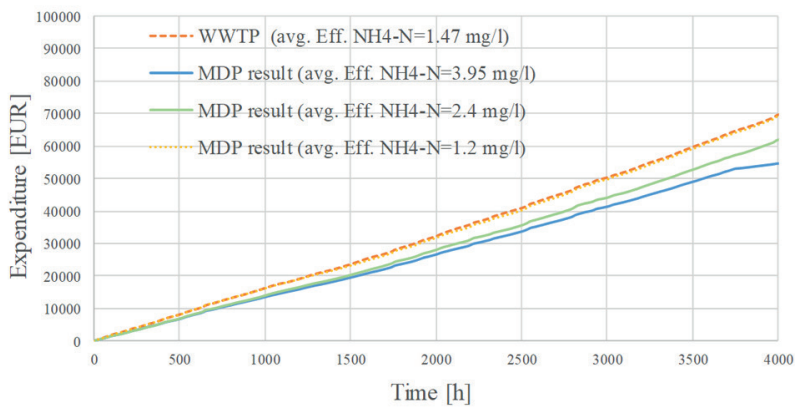

Fig. 14 Total expenditure: Red dotted curve shows the wastewater treatment's current total expenditure

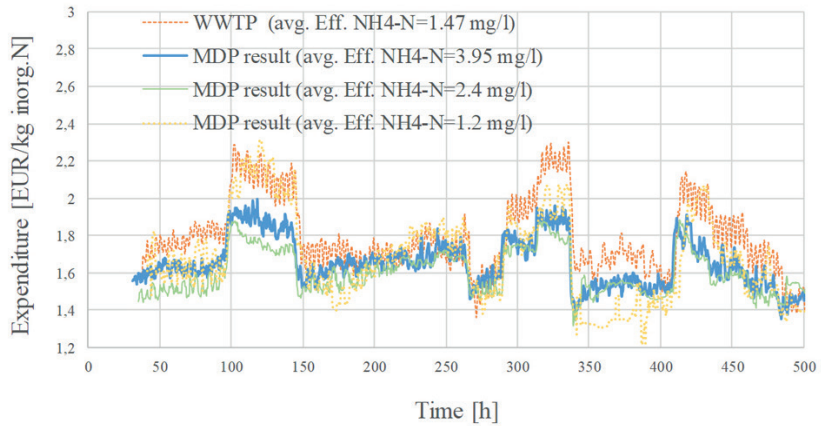

Fig. 15 Expenditure by specific inorganic $\mathrm{N}$ removal (EUR/kg N)

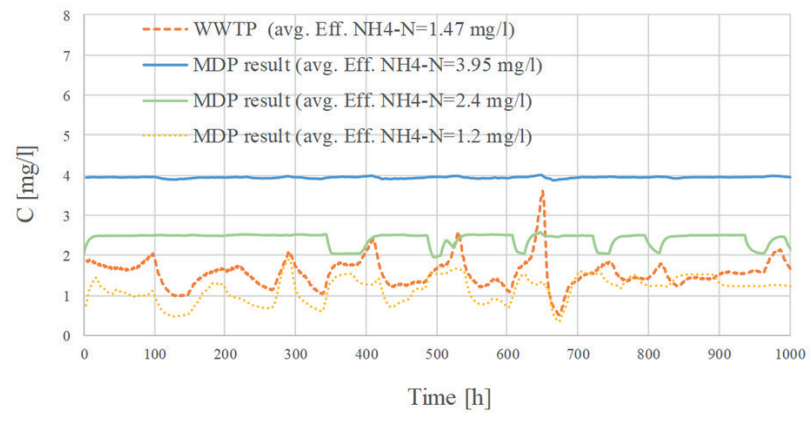

Fig. 16 Effluent NH4-N achieved by MDP policy schemes 
decision process model. The MDP was trained to optimize the current aeration scheme of an existing large wastewater treatment plant. With the presented method other intelligent intervention policies can be found, implementing the aspects of biokinetic processes into cost optimization. The results of the MDP intervention may also be integrated into logical program-driven operation control tools (PLCs), which is the further goal of this research. According to the model, there is a potential of achieving a maximum of $\sim 23 \%$ cost reduction, if the MDP scheme is applied.

\section{References}

[1] Azimi, S., Rocher, V. "Energy consumption reduction in a wastewater treatment plant", Water Practice and Technology, 12(1), pp. 104-116, 2017.

https://doi.org/10.2166/wpt.2017.006

[2] Ekici, K. "Energy Saving Preventions for Aeration Process in Wastewater Treatment Plant", Istanbul Technical University, Istanbul, Turkey, 2017.

https://doi.org/10.13140/RG.2.2.17054.74567

[3] Pakenas, J. L. "Energy Efficiency in Municipal Wastewater Treatment Plants", New York State Energy Research and Development Authority, Albany, NY, USA, 1995. [online] Available at: https://www.nyserda.ny.gov/-/media/Files/EERP/Commercial/ Sector/Municipal-Water-Wastewater-Facilities/energy-efficiency-in-municipal-wwtp.pdf [Accessed: 07 June 2019]

[4] Henze, M., Grady, Jr., C. P. L., Gujer, W., Marais, G. v. R., Matsuo, T. "Activated Sludge Model No. 1", In: Henze, M., Gujer, W., Mino, T., van Loosdrecht, M. (eds.) Activated Sludge Model ASM1, ASM2, ASM2d and ASM3, IWA Publishing, London, UK, 2000, pp. 1-37. https://doi.org/10.2166/9781780402369

[5] Henze, M., Gujer, W., Mino, T., Matsuo, T., Wentzel, M. C., Marais, G. v. R. "Activated Sludge Model No. 2", In: Henze, M., Gujer, W., Mino, T., van Loosdrecht, M. (eds.) Activated Sludge Model ASM1, ASM2, ASM2d and ASM3, IWA Publishing, London, UK, 2000, pp. 39-73.

[6] Rieger, L., Koch, G., Kühni, M., Gujer, W., Siegrist, H. "The eawag bio-p module for activated sludge model no. 3", Water Research, 35(16), pp. 3887-3903, 2001.

https://doi.org/10.1016/s0043-1354(01)00110-5

[7] Barker, P. S., Dold, P. L. "General Model for Biological Nutrient Removal Activated-Sludge Systems: Model Application", Water Environment Research, 69(5), pp. 985-991, 1997. [online] Available at: https://www.jstor.org/stable/25044949 [Accessed: 07 June 2019]

[8] Metcalf \& Eddy, Inc. "Wastewater Engineering - Treatment and Reuse", 4th ed., McGraw-Hill, New York, NY, USA, 2003.

[9] Siegrist, H., Renggli, D., Gujer, W. "Mathematical Modelling of Anaerobic Mesophilic Sewage Sludge Treatment", Water and Science Technology, 27(2), pp. 25-36, 1993.

https://doi.org/10.2166/wst.1993.0070

\section{Acknowledgement}

Support for the research and development project, was realized by the GINOP 2.1.7-15 (Economic and Innovative Operational Program titled "Prototype product development related to the decision support system for operation and planning of wastewater treatment plants" in 2018), as well as new theories could be researched and analyzed within the framework of FIKP 2018 - 47622/13.

[10] Vitasovic, Z. C., Zhou, S., McCorquodale, J. A., Lingren, K. "Secondary Clarifier Analysis Using Data from the Clarifier Research Technical Committee Protocol", Water Environment Research, 69(5), pp. 999-1007, 1997. [online] Available at: https:// www.jstor.org/stable/25044951 [Accessed: 07 June 2019]

[11] Hairer, E., Wanner, G., Nørsett, S. "Solving Ordinary Differential Equations I: Nonstiff Problems", Springer, Berlin, Heidelberg, Germany, 1993.

https://doi.org/10.1007/978-3-540-78862-1

[12] Cash, J. R., Karp, A. H. "A variable order Runge-Kutta method for initial value problems with rapidly varying right-hand sides", ACM Transactions on Mathematical Software, 16(3), pp. 201-222, 1990. https://doi.org/10.1145/79505.79507

[13] Rumelhart, D. E., Geoffrey, E. H., Williams, R. J. "Learning representations by back-propagating errors", Nature, 323, pp. 533-536, 1986.

https://doi.org/10.1038/323533a0

[14] Yadav, N., Yadav, A., Kumar, M. "An Introduction to Neural Network Methods for Differential Equations", Springer, Dordrecht, Netherlands, 2015.

https://doi.org/10.1007/978-94-017-9816-7

[15] Bellman, R. E. "Dynamic Programming", Princeton University Press, Princeton, NJ, USA, 2010.

[16] Press, W. H., Teukolsky, S. A., Vetterling, W. T., Flannery, B. P. "Numerical recipes", 3rd ed., Cambridge University Press, Cambridge, UK, 2007.

[17] Howard, R. A. "Dynamic Programming and Markov Processes", 1st ed., The MIT Press, Cambridge, MA, USA, 1960.

[18] NetJogtár "2003 LXXXIX. law on the environmental charge", [online] Available at: https://net.jogtar.hu/jogszabaly?docid=A0300089.TV [Accessed: 19 June 2019] (in Hungarian)

[19] Brun, R., Kühni, M., Siegrist, H., Gujer, W., Reichert, P. "Practical identifiability of ASM2d parameters -systematic selection and tuning of parameter subsets", Water Research, 36(16), pp. 4113-4127, 2002 .

https://doi.org/10.1016/S0043-1354(02)00104-5 